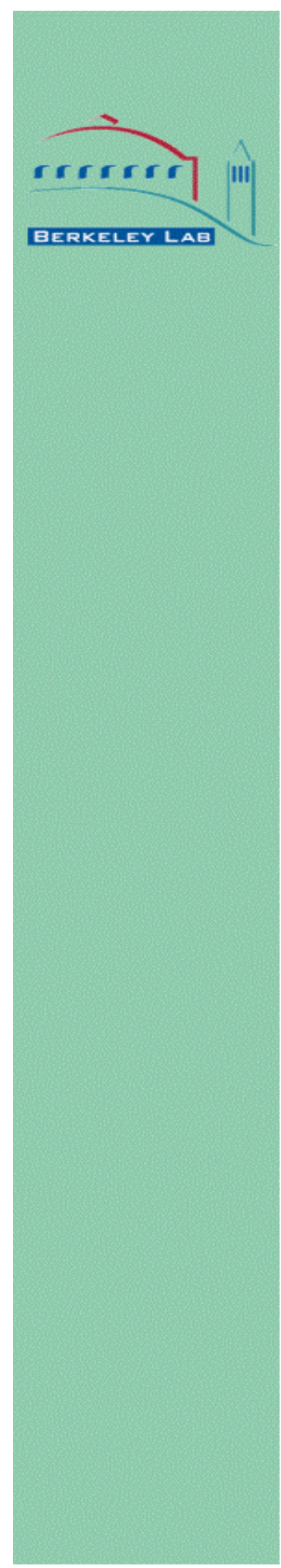

ERNEST ORLANDO LAWRENCE

BERKELEY NATIONAL LABORATORY

\title{
Benefits and Costs of Aggressive Energy Efficiency Programs and the Impacts of Alternative Sources of Funding: Case Study of Massachusetts
}

Peter Cappers, Andrew Satchwell, Charles Goldman, and Jeff Schlegel

Preprint version of paper for conference proceedings, ACEEE Summer Study, Pacific Grove, CA, Aug. 15-20, 2010

Environmental Energy Technologies Division

August 2010

The work described in this report was funded by the U.S. Department of Energy Office of Electricity Delivery and Energy Reliability (OE) - Permitting, Siting and Analysis Division under Contract No. DE-AC02-05CH11231. 


\section{Disclaimer}

This document was prepared as an account of work sponsored by the United States Government. While this document is believed to contain correct information, neither the United States Government nor any agency thereof, nor The Regents of the University of California, nor any of their employees, makes any warranty, express or implied, or assumes any legal responsibility for the accuracy, completeness, or usefulness of any information, apparatus, product, or process disclosed, or represents that its use would not infringe privately owned rights. Reference herein to any specific commercial product, process, or service by its trade name, trademark, manufacturer, or otherwise, does not necessarily constitute or simply its endorsement, recommendation, or favoring by the United States Government or any agency thereof, or The Regents of the University of California. The views and opinions of authors expressed herein do not necessarily state or reflect those of the United States Government or any agency thereof or The Regents of the University of California.

Ernest Orlando Lawrence Berkeley National Laboratory is an equal opportunity employer. 


\section{Acknowledgments}

The work described in this report was funded by the U.S. Department of Energy Office of Electricity Delivery and Energy Reliability (OE) - Permitting, Siting and Analysis Division under Contract No. DE-AC02-05CH11231.

The authors would like to thank Larry Mansueti (DOE OE) for their support of this project. The authors would also like to thank Phil Guidice, Frank Gorke and Mike Sherman (Massachusetts DOER) and Tim Wolfe (MA DPU) for their comments and feedback on draft work products from this study. 
LBNL-3833E

\title{
Benefits and Costs of Aggressive Energy Efficiency Programs and the Impacts of Alternative Sources of Funding: \\ Case Study of Massachusetts
}

\author{
Principal Authors \\ Peter Cappers, Andrew Satchwell, Charles Goldman, and Jeff Schlegel
}

August 2010

The work described in this report was funded by the U.S. Department of Energy Office of Electricity Delivery and Energy Reliability (OE) - Permitting, Siting and Analysis Division under Contract No. DE-AC02-05CH11231. 


\section{Table of Contents}

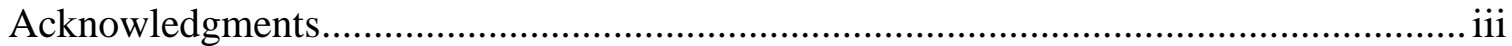

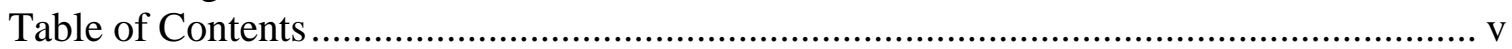

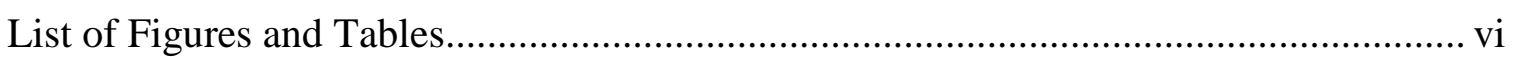

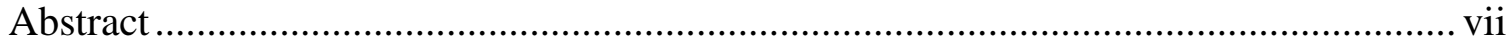

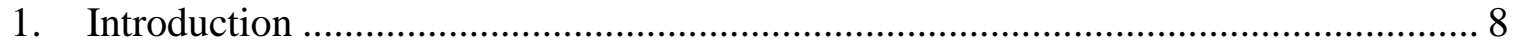

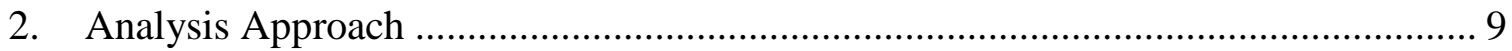

3. Characterizing the Massachusetts Electricity Market ......................................... 10

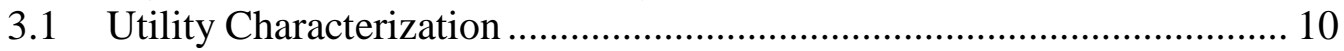

3.2 Energy Efficiency Portfolio Characterization ..................................... 11

3.3 Funding Sources of Energy Efficiency ….......................................... 13

3.4 Other Business Model Considerations ................................................... 15

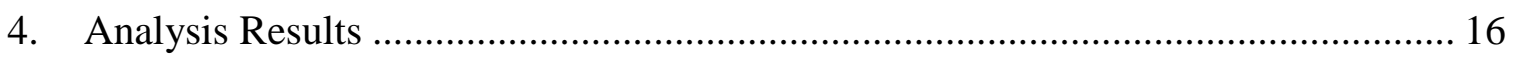

4.1 Impacts of Aggressive EE Portfolio on Ratepayers .............................. 16

4.2 Impact of Aggressive EE Portfolio on Utility Shareholders .................. 18

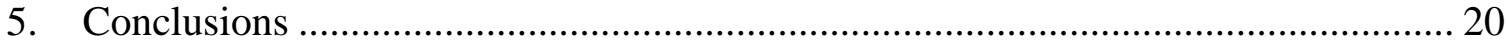

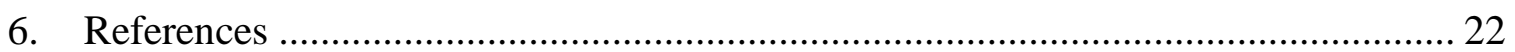




\section{List of Figures and Tables}

Figure 1. Flowchart for Quantitative Analysis of Energy Efficiency Impacts on

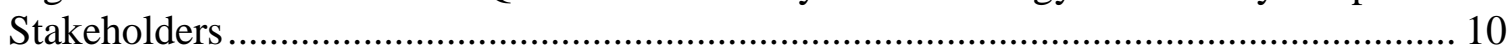

Figure 2. Effect of Energy Efficiency Portfolios on Massachusetts “Super-Utility” Load

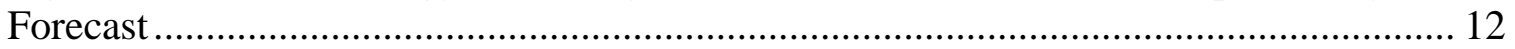

Figure 3. Relationship of Various Energy Efficiency Funding Sources to Alternative EE

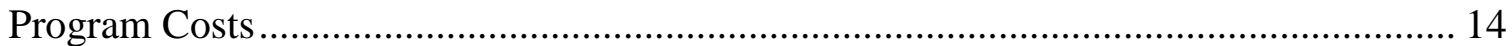

Figure 4. Nominal Total Ratepayer Bill Comparison (2009-2020) ................................ 17

Figure 5. Nominal All-In Retail Rate Comparison (2009-2020) .................................... 18

Figure 6. Effects of Alternative Efficiency Business Models Components on ROE (2009-

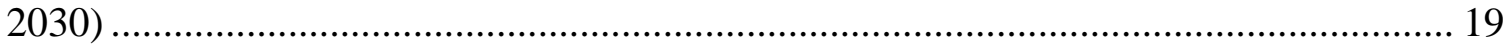

Figure 7. Effects of Alternative Energy Efficiency Business Model Components on

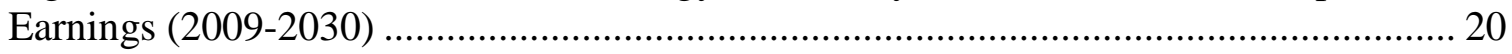

Table 1. Lifetime Savings, Resource Costs and Benefits of Alternative Energy Efficiency

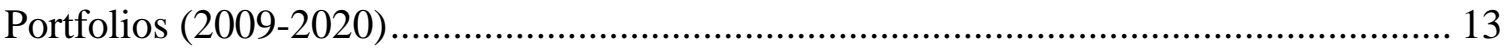

Table 2. Change in Ratepayer Bills due to Energy Efficiency (\$B, 2009-2030 PV relative

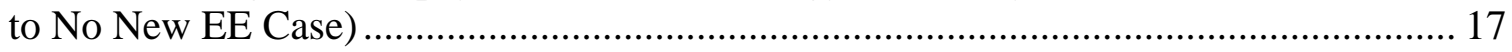
Table 3. Change in All-In Retail Rates due to Energy Efficiency ( $\mathbb{\$} / \mathrm{kWh}, 2009-2030$ average relative to No New EE Case). 18 


\begin{abstract}
Increased interest by state (and federal) policymakers and regulatory agencies in pursuing aggressive energy efficiency efforts could deliver significant utility bill savings for customers while having long-term implications for ratepayers (e.g. potential rate impacts). Equity and distributional concerns associated with the authorized recovery of energy efficiency program costs may necessitate the pursuit of alternative program funding approaches.

In 2008, Massachusetts passed the Green Communities Act which directed its energy efficiency (EE) program administrators to obtain all cost-effective EE resources. This goal has translated into achieving annual electric energy savings equivalent to a $2.4 \%$ reduction in retail sales from energy efficiency programs in 2012. Representatives of electricity consumer groups supported the new portfolio of EE programs (and the projected bill savings) but raised concerns about the potential rate impacts associated with achieving such aggressive EE goals, leading policymakers to seek out alternative funding sources which can potentially mitigate these effects. Utility administrators have also raised concerns about under-recovery of fixed costs when aggressive energy efficiency programs are pursued and have proposed ratemaking policies (e.g. decoupling) and business models that better align the utility's financial interests with the state's energy efficiency public policy goals. Quantifying these concerns and identifying ways they can be addressed are crucial steps in gaining the support of major stakeholder groups - lessons that can apply to other states looking to significantly increase savings targets that can be achieved from their own ratepayer-funded energy efficiency programs.

We use a pro-forma utility financial model to quantify the bill and rate impacts on electricity customers when very aggressive annual energy efficiency savings goals $(\sim 2.4 \%)$ are achieved over the long-term and also assess the impact of different cost recovery approaches that integrate alternative revenue sources. We also analyze alternative lost fixed cost recovery approaches to better understand how to mitigate the erosion of utility shareholder returns in states that have adopted (and achieved) very aggressive savings targets.
\end{abstract}




\section{Introduction}

Regulators and legislators in many states are increasingly interested in pursuing aggressive energy efficiency (EE) savings as a means to offset the potentially higher costs and environmental impacts associated with many new generation resources and mitigate the effects of climate change. Ratepayer-funded EE programs are a common means of delivering these savings. Currently 31 states have legislative or regulatory policies in place that identify the need to assess the cost-effectiveness and/or pursue ratepayer-funded EE programs; although as of 2007, reductions in electricity sales due to ratepayer-funded EE programs were modest (less than or equal to $0.1 \%$ ) in 11 of these states (Eldridge et al. 2009). There are ample business reasons why a regulated utility would eschew EE efforts (Jensen 2007). Thus, states are increasingly adopting policies that set explicit savings goals for utilities through legislative or regulatory requirements and/or attempt to align the utility's business and financial interests with broader public policy objectives that support energy efficiency. For example, eleven states have adopted an energy efficiency resource standard (EERS) within the last three years (Barbose et al. 2009).

This study examines (1) the customer bill and rate impacts, and (2) the shareholder earnings and return on equity (ROE) impacts when a state decides to significantly expand its ratepayer-funded EE programs. We model our analysis based on the Massachusetts Green Communities Act (GCA) (Mass. Gen. Laws ch. 25, § 21, 2008), which directed its EE program administrators (PAs) to achieve all cost-effective energy efficiency. The final PA compliance filings to the Massachusetts Department of Public Utilities (DPU) indicated the programs would produce annual electric energy savings equivalent to a $2.4 \%$ reduction in retail sales in 2012, among the most aggressive energy efficiency targets in the nation. ${ }^{1}$ Our study builds on PA and DPU analyses that evaluated the short-term rate and bill impacts during the term of the approved three-year EE program budgets. We provide a long-term assessment of impacts on ratepayers and shareholders as we examine energy efficiency programs that achieve these savings reduction targets (2.4\% per year) through 2020 with impacts over a 22-year time-horizon (2009-2030) to fully capture the benefits over the installed measures' useful lifetimes.

We characterize and model a Massachusetts "super-utility", an entity that reflects the aggregate characteristics of the Commonwealth's seven major electric operating companies (EOCs) to report aggregate ratepayer and shareholder impacts. We analyze two EE portfolios: (1) a "business-as-usual" (BAU) EE scenario where an approximate $0.9 \%$ annual savings goal is maintained through 2020; and (2) an Aggressive (Agg.) EE scenario with a 2.4\% annual savings goal representing proposed savings levels that the DPU has ruled comply with the "all costeffective energy efficiency provisions" of the Massachusetts Green Communities Act. Our Aggressive EE portfolio is based on program offerings that have been approved by the Massachusetts DPU in the PAs' most recent energy efficiency plans (2010-2012). ${ }^{2}$

We focus the analysis on ratepayer concerns, specifically cost-recovery issues and their impact on ratepayers under the Aggressive EE portfolio relative to our BAU case with the inclusion of additional revenue sources that can mitigate rate and bill impacts. We isolate the

\footnotetext{
${ }^{1}$ The Massachusetts energy savings goals were developed and proposed initially by the Energy Efficiency Advisory Council, a legislatively-appointed advisory body overseeing energy efficiency programs in the state.

${ }^{2}$ Commonwealth of Massachusetts Department of Public Utilities. Docket Nos. 09-116 through 09-120. January 28, 2010.
} 
marginal rate and bill impacts of each of three different alternative revenue sources: Regional Greenhouse Gas Initiative (RGGI) auction revenues, ISO-New England (ISO-NE) Forward Capacity Market (FCM) auction revenues, and other funding sources including the use of outside capital for financing. We also include an analysis of utility shareholder concerns, assessing effects on earnings and ROE under the Aggressive EE portfolio relative to the BAU case. The shareholder impact analysis compares a straight full decoupling mechanism with a k-factor to a lost-base revenue mechanism to isolate the marginal impacts of alternative lost-fixed cost recovery approaches in the pursuit of the Aggressive EE savings goals.

The remainder of the paper discusses the study approach (including the utility financial characterization, EE portfolios, and ratepayer and shareholder impact scenarios), presents analysis results, and concludes with key findings and policy discussion.

\section{Analysis Approach}

We used a pro-forma, spreadsheet-based financial model adapted from a tool (Benefits Calculator) constructed to support the National Action Plan for Energy Efficiency (Cappers et al. 2009a). This model builds on previous work on shareholder incentives (Cappers et al. 2009b, 2009c) by including additional sources of revenue to fund energy efficiency programs. The major steps in our analysis are depicted in Figure 1. Two main inputs are required: (1) a characterization of the utility which includes its initial financial and physical market position, a forecast of the utility's future sales, peak demand, and resource strategy and estimated costs to meet projected growth; and (2) a characterization of the EE portfolio - projected electricity and demand savings, costs and useful lifetime of a portfolio of energy efficiency programs that the utility is planning or considering to implement during the analysis period. ${ }^{3}$ The Benefits Calculator also estimates total resource costs and benefits of the EE portfolio using a forecast of avoided capacity and energy costs. The Benefits Calculator uses inputs provided in the Utility Characterization to produce a base case that does not include any new energy efficiency programs (No New EE) as well as alternative scenarios that include different energy efficiency resource savings levels, various treatments of $\mathrm{EE}$ funding sources, and alternative EE business models (With EE).

\footnotetext{
${ }^{3}$ Our analysis does not include the effects of demand response programs.
} 
Figure 1. Flowchart for Quantitative Analysis of Energy Efficiency Impacts on Stakeholders

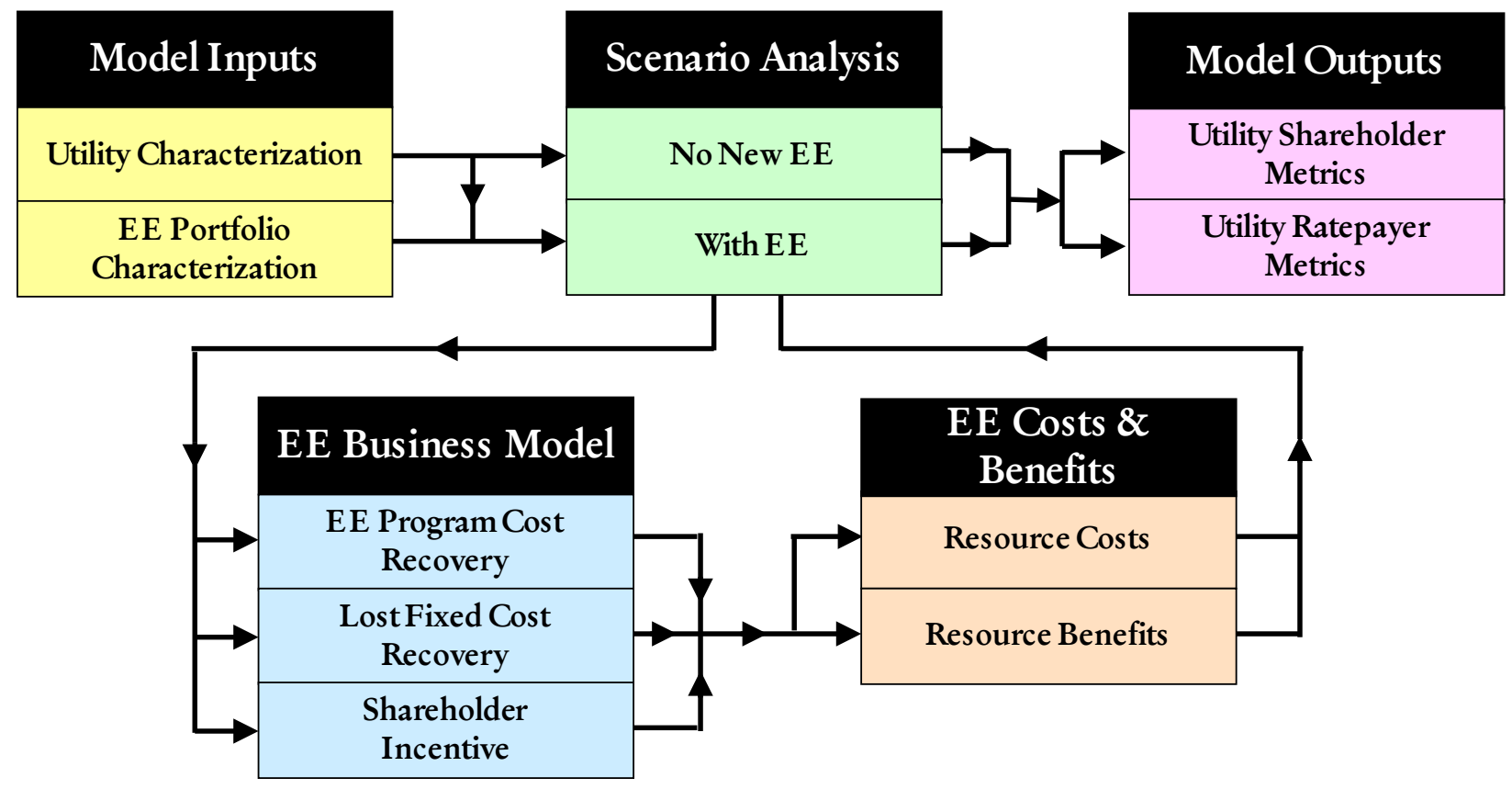

\section{Characterizing the Massachusetts Electricity Market}

\subsection{Utility Characterization}

We reviewed the physical and financial characteristics of all major electric operating companies (EOCs) in Massachusetts: Boston Edison, Cambridge Electric, Commonwealth Electric, Fitchburg Gas \& Electric, Massachusetts Electric, Nantucket Electric, and Western Massachusetts Electric. To construct the financial representation of each EOC, we used historic FERC Form 1 and most recent general rate case data to construct a relationship between the growth in peak demand and growth in costs which was used to develop a long-range cost forecast for 2009 to 2030. Based on this assessment, we combined the individual utility characteristics to construct a single Massachusetts "super-utility", which would serve as the basis for our analysis.

The Massachusetts “super-utility” has first-year (2009) annual retail sales of $\sim 46,000$ GWh and an initial peak demand of $\sim 11,900 \mathrm{MW}$, which are inclusive of the impacts from historical energy efficiency programs. Going forward, in the base case, we assume that the Massachusetts "super-utility" does not offer any new energy efficiency programs. ${ }^{4}$ Sales are forecasted to grow at a compound annual rate of $1.2 \%$, while peak demand is expected to

\footnotetext{
${ }^{4}$ The ISO New England (ISO-NE) derives load and peak demand forecasts that do not directly account for future energy efficiency efforts but likely do include impacts from historical energy efficiency programs. For this reason and to more accurately capture the marginal effects of different levels of energy efficiency on stakeholders' financial positions, we have not included the effects from any new energy efficiency programs that might be offered by the Massachusetts Program Administrators (PAs), a.k.a. EOCs, in this “No New EE” case.
} 
increase at a slightly faster rate of $1.3 \%$ per year. The "super-utility" has 2.6 million customers in 2009 and expects very modest customer account growth of $0.3 \%$ per year. Massachusetts restructured its electric industry in 1997 by fully deregulating supply service from delivery, thereby eliminating the EOCs' ability to build, own and earn a return on generation assets under cost-ofservice regulation (Mass. Gen. Laws ch. 164, § 1A, 1997). The EOCs procure half of the basic service residential and commercial customers' power supply for a twelve month term through semi-annual competitive solicitations ${ }^{5}$; changes in commodity costs are passed through to ratepayers. Increases in non-fuel expenses are reflected in retail rates after the DPU has issued an order in a general rate case or other regulatory filing. With sales and peak demand growing at $1.2 \%$ and $1.3 \%$ per year, respectively, and customer growth expected to be modest $(0.3 \%$ annually), revenue growth between rate cases is not anticipated to keep pace with the 1.9\% annual growth in non-fuel expenses. Thus, the "super-utility" is unable to achieve its authorized ROE of $10.98 \%$. Without a decoupling mechanism to mitigate the revenue erosion between rate cases in the "No New EE" scenario, the utility files a rate case triennially (i.e., every third year) to reduce the detrimental impact on shareholder returns. ${ }^{6}$

\subsection{Energy Efficiency Portfolio Characterization}

The Commonwealth of Massachusetts has a rich history of pursuing energy efficiency, and has recently set energy savings goals among the most ambitious in the country. We have constructed two EE portfolios to capture these alternative savings and spending scenarios that start offering programs in 2009 and end in 2020 (see Figure 2).

The first energy efficiency portfolio represents a "business-as-usual" (BAU) case as if the Commonwealth had not passed the GCA but simply continued on its pre-existing path of capturing energy efficiency savings of $\sim 350 \mathrm{GWh}$ /year on a nominal 2009 budget of \$135M. ${ }^{7}$ Over the 12 year time horizon the EE programs are offered, total energy savings of 40,737 GWh are achieved in this scenario which provide \$4.1B (PV) in net resource benefits between 2009 and 2030 (see Table 1). ${ }^{8}$ Program administration and measure costs are assumed to grow at a nominal annual rate of $2.5 \%$.

The second portfolio, “Aggressive EE”, represents savings and expenditure levels based on energy efficiency programs contained in the recently approved three-year plans filed by each

\footnotetext{
${ }^{5}$ EOCs procure basic service electricity supply for industrial customers on a quarterly basis.

${ }^{6}$ Rate case filings are assumed to use a historic test year. Generally there is a six-month lag between the time a general rate case is filed and the time the DPU issues an order; however, our financial model is only able to accommodate full years. Based on discussions with staff at the Massachusetts Department of Energy Resources (DOER), we have chosen to not include any lag between the filing and implementation of rates.

7 The year 2009 was actually a transition year towards the aggressive savings goals required under Massachusetts' Green Communities Act that was passed in 2008. Our BAU EE scenario attempts to represent expected levels of EE absent the passage of the GCA and at program budget levels constrained by system benefits charge funds assumed to be available that year ( $\$ 135 \mathrm{M})$.

${ }^{8}$ In the calculation of resource benefits, we are not including any non-electric benefits (e.g., water savings, avoided alternative fuel savings, etc.) but are including avoided cost of energy, avoided cost generation capacity, avoided cost of T\&D capacity, and the Demand Response Induced Price Effect (DRIPE). Avoided cost forecasts were taken from Hornby et al. (2009), which show avoided energy costs starting at $\sim$ \$60/MWh in 2009 and growing annually at a nominal rate of $7.5 \%$. With respect to resource costs, we are not including the shareholder incentive or the lost fixed cost recovery mechanism.
} 
of the Massachusetts PAs in compliance with the GCA. ${ }^{9}$ At the end of the three-year period (2012), the EE programs will have ramped up to provide annual energy savings of $\sim 1,100 \mathrm{GWh}$ in 2012, equivalent to $\sim 2.4 \%$ of retail electricity sales, at a nominal total resource cost of $\$ 714 \mathrm{M}$. This absolute savings level is assumed to be continued through 2020, producing total lifetime energy savings of $115,255 \mathrm{GWh}$, with administrative and measure costs rising by $2.5 \%$ annually, resulting in a total resource cost of $\$ 4.9 \mathrm{~B}(\mathrm{PV})$ and generating net resource benefits of $\$ 11.2 \mathrm{~B}$ (PV).

In both portfolios, $\sim 70 \%$ of electric savings comes from commercial and industrial EE programs and 30\% from residential EE programs. In Massachusetts, savings from residential lighting programs are decreasing due in large part to federal lighting standards. Other "nonlighting" residential opportunities are somewhat limited given the climate and penetration of non-electric based heating, ventilation, and air-conditioning systems. ${ }^{10}$ Customer cost contributions account for $\sim 17 \%$ of incremental measure costs in the residential and low-income programs, and $\sim 40 \%$ of incremental measure costs in the commercial and industrial programs.

Figure 2. Effect of Energy Efficiency Portfolios on Massachusetts “Super-Utility” Load Forecast

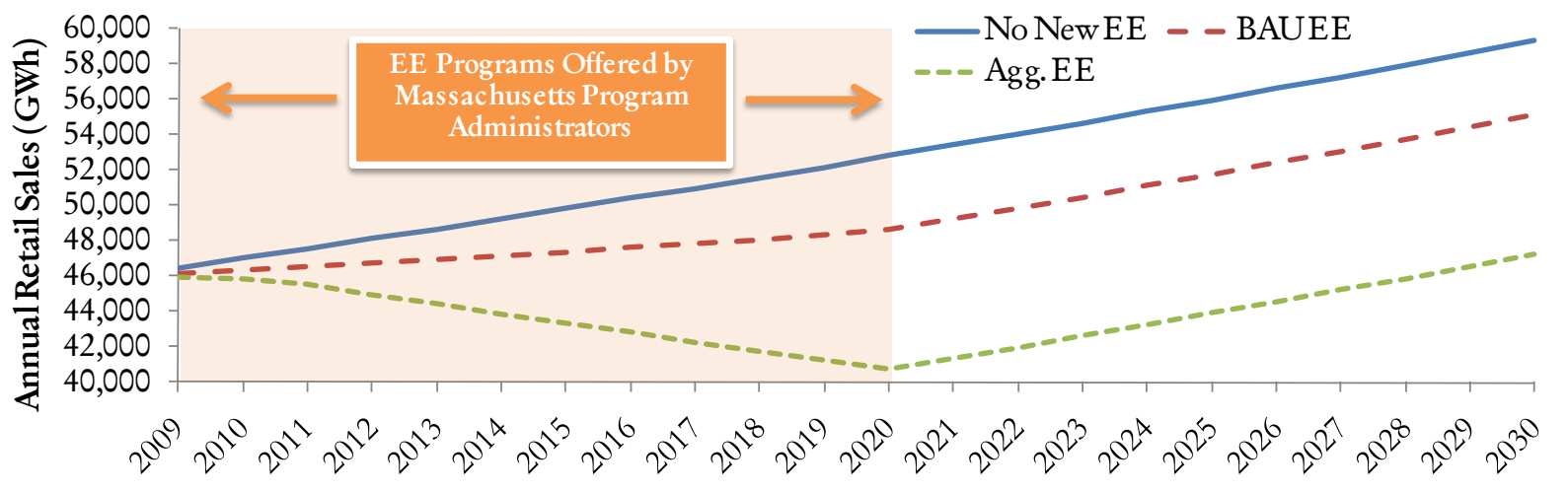

\footnotetext{
${ }^{9}$ For purposes of this analysis and using the approach of the "MA super-utility," the energy efficiency program administrators and electric operating companies are synonymous, and thus the terms will be used interchangeably.

${ }^{10}$ Our EE portfolios are consistent with the GCA compliance filings of the Massachusetts PA and include programs that are "fuel neutral" and achieve reductions and financial benefits associated with fuels other than electricity (e.g., oil, natural gas). This analysis, however, only addresses the electric impacts (costs and benefits) from these EE programs.
} 
Table 1. Lifetime Savings, Resource Costs and Benefits of Alternative Energy Efficiency Portfolios (2009-2020)

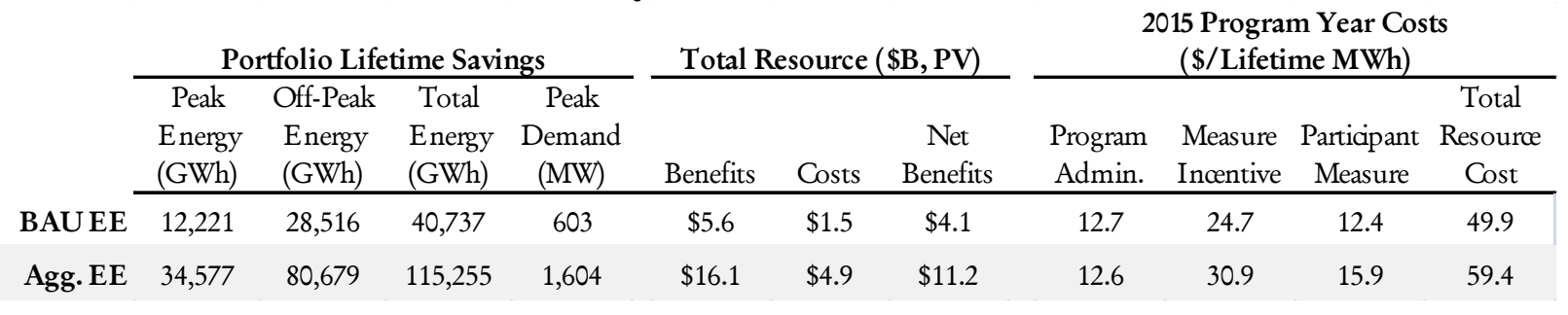

\subsection{Funding Sources of Energy Efficiency}

We model two methods for directly recovering authorized EE program expenditures from ratepayers, which are loosely based on the way Massachusetts has historically funded energy efficiency programs (see Figure 3). First, a systems benefit charge (SBC) of 3 mills/kWh (nominal) is assessed to all ratepayers' consumption. ${ }^{11}$ This generates $\sim \$ 134 \mathrm{M}$ in 2009 and serves as the budget for our BAU EE portfolio in that year. A second charge, Energy Efficiency Surcharge (EES), is assessed to nearly all ratepayers but varies from year-to-year in order to ensure that authorized EE program expenditures are completely recovered by the program administrators in years where the energy efficiency program budgets exceed the revenues collected under the SBC.

Implementing the Aggressive EE portfolio will result in a significant increase in program costs - from $\sim \$ 140 \mathrm{M} /$ year under the BAU EE scenario in 2012 to $\$ 523 \mathrm{M} /$ year under the Aggressive EE scenario. In an attempt to alleviate some of the customer rate and bill impacts caused by this nearly four-fold increase in costs, Massachusetts regulators and policymakers have identified three alternative revenue sources that could be used to reduce the share of costs borne by electricity consumers (see Figure 3).

\footnotetext{
${ }^{11}$ In reality, Massachusetts' SBC is set at $2.5 \mathrm{mills} / \mathrm{kWh}$. To simplify the analysis, and to facilitate a direct analytical comparison in this paper between SBC-only funding and the use of alternative revenue sources, we increased the SBC to 3 mills $/ \mathrm{kWh}$ to fully accommodate and fully fund, with the SBC alone, the budget required to achieve the BAU EE savings level.
} 
Figure 3. Relationship of Various Energy Efficiency Funding Sources to Alternative EE Program Costs

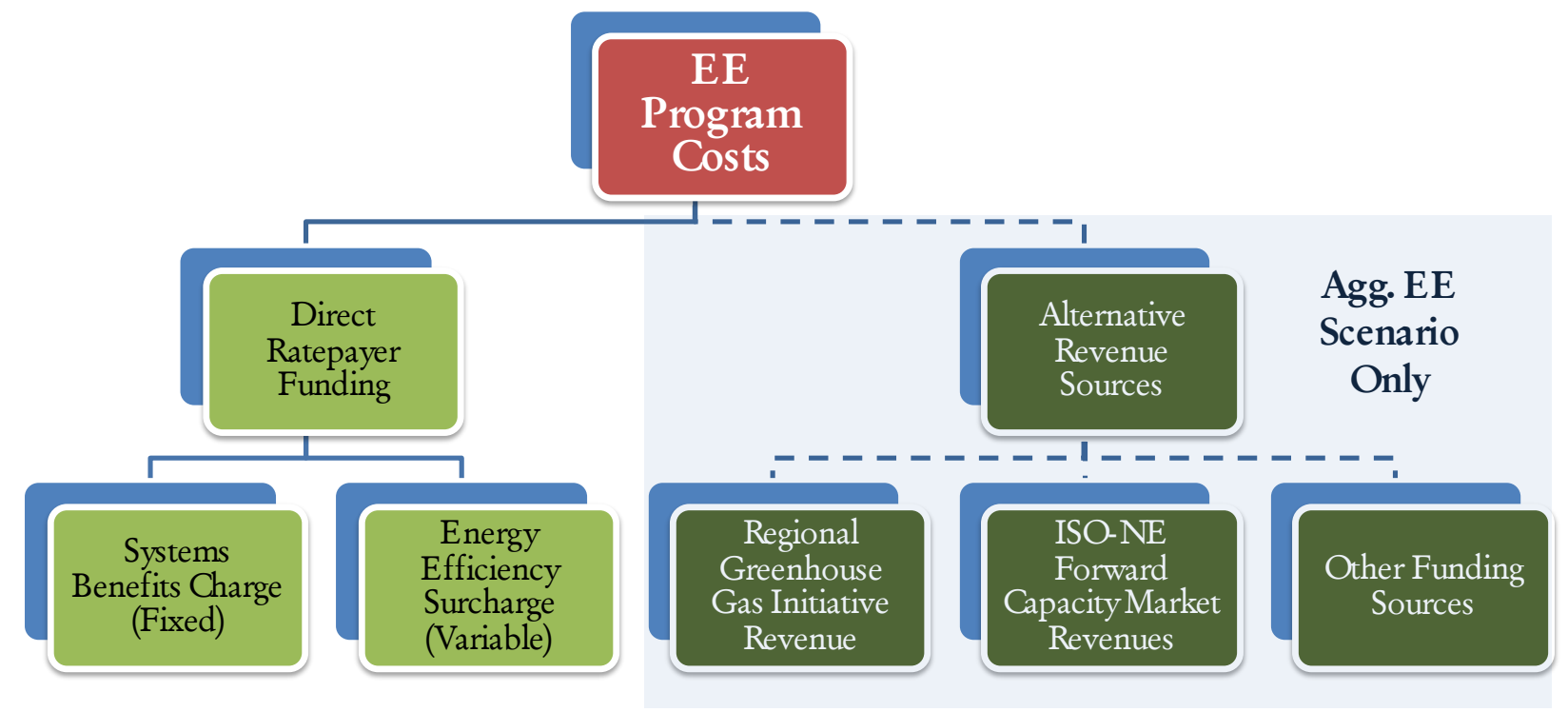

Regional Greenhouse Gas Initiative (RGGI). RGGI is a cap-and-trade carbon emissions reduction program with participation by ten Northeast states including Massachusetts. The RGGI program caps regional carbon emissions at 1990 historic levels in 2014 and reduces to $10 \%$ below this level in 2018. Massachusetts has its own state emissions budget12 and suppliers must procure these allotments to cover their carbon emissions. Given the electric supply procurement system in Massachusetts, it is likely that suppliers will pass through these higher supply costs as a result of RGGI directly to ratepayers. The Green Communities Act directed that at least $80 \%$ of the revenue generated by Massachusetts' sale of its RGGI allotments will go to the program administrators to reduce ratepayers' share of authorized energy efficiency program budgets.

Forward Capacity Market (FCM). The ISO-NE FCM is a wholesale capacity market covering six New England states which allows various types of demand-side and supply-side resources to participate as qualified capacity providers. ISO-NE projects three-years forward the reliability needs of the regional power system and conducts a single auction to procure $100 \%$ of the capacity requirement to meet these needs. Energy efficiency is able to directly participate in the auctions as a resource and is paid the FCM auction-clearing price for providing capacity. The Massachusetts PAs determine their own bidding strategy of energy efficiency resources and receive direct payments from ISO-NE. The Massachusetts DPU has directed the PAs to directly apply these payments to energy efficiency program costs in order to reduce ratepayers' share. In addition to having a direct financial benefit, energy efficiency can also indirectly influence future system needs, with a one-year lag in the case of the ISO-NE FCM, because of timing when the capacity obligation is set and when the impacts of energy efficiency on peak demand levels inure.

${ }^{12}$ Budgeted allotments are detailed in 310 CMR 7.70 5(a). 
Other funding sources. Massachusetts PAs have committed to the pursuit of securing other funding sources and have explored acquiring new sources of outside capital for financing options to reduce the financial barriers to customer investments in energy efficiency. Two types of other funding are planned: other program funding and other capital for financing. Thus, other program funding sources serve as an implicit reduction in costs to ratepayers if utilized. Sources of other funding may include federal stimulus, energy, or climate funds, foundation support, and market sources of capital for financing. ${ }^{13}$

\subsection{Other Business Model Considerations}

The pursuit of aggressive EE goals will require a viable business model from the perspective of utility shareholders. Such a business model would address the following issues: recovery of prudently incurred program costs, possible under-recovery of fixed cost between rate cases due to reduced sales from energy efficiency, and development of a shareholder incentive that provides an opportunity for energy efficiency to become a "profit center" for the administrator. The discussion above focused on how the PA recovers authorized EE program costs, and below we address the latter two issues.

The Green Communities Act provides for performance incentive payments to the PA for success in meeting or exceeding goals (Mass. Gen. Laws ch. 25, § 21(b)(2), 2008). The recently enacted Massachusetts shareholder incentive mechanism is comprised of three components: (1) a savings mechanism, which is based on the total benefits achieved; (2) a value mechanism, which is based on the net benefits achieved; and (3) performance metrics, which direct PA efforts into specific areas or to address specific issues (e.g., low-income, community initiatives, other funding sources, expanded financing). In its final decision, the Massachusetts Department of Public Utilities (DPU) established a total statewide incentive pool that approximately equals 3\% (on an after-tax basis, or about 5\% pre-tax) of each PA's energy efficiency budget, which is provided to the PA upon meeting or exceeding the goals stipulated in the three components listed above.

The shareholder incentive mechanism in Massachusetts does not appear to be a major point of contention between PA and their regulators, so we have chosen not to model alternative versions. Instead, we assume the PAs meet the savings targets and component goals, thereby allowing them to fully collect 3\% (after-tax) of aggregate program expenditures provided to them under the shareholder incentive mechanism.

Given the magnitude of the energy efficiency savings being proposed in Massachusetts, revenue erosion between rate cases will likely become a major concern for utilities in the achievement of these goals. All Massachusetts PAs currently have a Lost Base Revenue (LBR) mechanism, which in our analysis values the reduction in sales from the three prior years' EE programs at the existing non-fuel retail rate. This approach to dealing with the under-recovery of fixed-costs was deemed by policymakers in the GCA to potentially be insufficient when such aggressive savings levels are achieved, so legislators directed the DPU to allow PAs to propose

${ }^{13}$ Another policy mechanism beyond the use of alternative revenue and other funding sources to reduce ratepayer bill impacts is the amortization of authorized program costs. Although not explicitly considered by the Massachusetts DPU, it is a policy tool that may be considered in some states in the future, but not in this analysis. 
comprehensive decoupling mechanisms. To date, the DPU has approved a decoupling mechanism for only one electric utility; other utilities have proposed different forms of decoupling which will likely be ruled on by the DPU in the near future. ${ }^{14}$

We are interested in assessing the impacts on ratepayers and shareholders when different methods for recovering authorized fixed costs are employed. To be consistent with the progression of approaches used in Massachusetts, we first apply a LBR mechanism in both the BAU and Aggressive EE cases, similar in design to that which the Massachusetts PAs use currently; limit recovery to the first 3 years after a measure is installed or the next rate case, which ever happens first. Then, only in the case of the Aggressive EE portfolio do we apply a straight sales-based decoupling (Dec.) mechanism with a k-factor (i.e., net inflation adjustment factor) to account for cost growth between rate cases. The k-factor is designed to allow the super-utility, when implementing the Aggressive EE portfolio, to remove the effect of any reduction in the recovery of fixed costs directly caused by the reduction in revenue from lesser retail sales. This makes the PA financially indifferent between the pursuit of the aggressive EE goals or lack thereof (No New EE) and may also provide an opportunity for additional earnings from energy efficiency as part of a comprehensive EE business model (i.e. decoupling combined with a shareholder incentive).

\section{Analysis Results}

We focused our analysis effort on assessing the impacts of implementing an Aggressive EE portfolio, relative to the BAU EE portfolio, on customers' bills and rates and on utility earnings and ROE. We identified several alternative revenue sources that could be used to reduce ratepayers' share of EE utility program costs. We then focused on developing a more robust EE business model by applying a decoupling mechanism when the utility achieves the Aggressive EE savings goals to assess the degree to which it will improve the financial outlook for shareholders and at what cost to ratepayers.

\subsection{Impacts of Aggressive EE Portfolio on Ratepayers}

The energy efficiency efforts undertaken by our Massachusetts "super-utility” provide significant net resource benefits: \$4.1B (PV) for the BAU EE portfolio and \$11.2B (PV) for the Aggressive EE portfolio (see Table 1). The two portfolios also have substantial bill savings and rate impacts over both the short and long-term. ${ }^{15}$ Implementing the BAU EE portfolio would decrease ratepayer bills, in relation to the No New EE case, by an average of $\$ 240 \mathrm{M}$ a year between 2009 and 2020, when EE programs are administered. Aggregate customer bills decrease by $\$ 560 \mathrm{M}$ per year on average, under the Aggressive EE portfolio compared to the No New EE case) (see Figure 4). However, note that ratepayers as a whole do not immediately begin to see bill savings, but do so within a relatively short period of time: three years (i.e., 2011) under the BAU No EE portfolio and three to four years (i.e., 2011-2012) for the Aggressive EE portfolio. This occurs because the utility cost savings associated with these energy efficiency portfolios

\footnotetext{
${ }^{14}$ Commonwealth of Massachusetts Department of Public Utilities. Docket No. 09-39. November 30, 2009.

${ }^{15}$ The Benefits Calculator model used to perform this analysis only provides aggregate ratepayer effects that cannot be broken out by participants or non-participants in the administered EE programs.
} 
take time to develop and inure to ratepayers (based on the timing of general rate case filings) and are offset by annual EE program expenditures that ratepayers must cover. In addition, the costs of the energy efficiency programs are expensed during each program year, and the energy savings and other benefits accrue over the lifetimes of the measures. Thus, in this situation, a short-term analysis might not fully capture the bill reductions that would occur and inure to consumers as a whole, depending upon the time horizon chosen.

From a long-term perspective (2009-2030), ratepayers as a whole would experience bill savings from the BAU EE portfolio equal to $\$ 3.5 \mathrm{~B}$ (PV) or 3.3\%, while the Aggressive EE portfolio generates $\$ 9.1 \mathrm{~B}(\mathrm{PV}$ ) or $8.7 \%$ reduction in aggregate bills (without the application of additional EE revenue sources), relative to the No New EE case (see Table 2). The bill savings in our analysis account for and are net of any rate increases necessary to fund the increased energy efficiency. Applying revenues from ISO-NE Forward Capacity Market would further reduce aggregate ratepayer bills over the 22 year analysis period by $\sim \$ 210 \mathrm{M}(\mathrm{PV})$, revenues from the auction of RGGI allotments would provide \$340M (PV) reduction in bills, and the use of Other Funding Sources would reduce the costs to ratepayers by an additional $\$ 660 \mathrm{M}(\mathrm{PV})$. If all three additional revenue sources are applied, ratepayers would see their bills reduced by an additional $\sim$ 1.2B (PV), resulting in a $9.8 \%$ or $\$ 10.35 \mathrm{~B}$ (PV) savings to ratepayers relative to the case if Massachusetts regulators ordered all new energy efficiency programs to cease being offered and $\sim \$ 6.9 \mathrm{~B}$ or $6.7 \%$ in savings from achieving the Aggressive EE goals instead of the BAU EE goals (see Table 2).

Figure 4. Nominal Total Ratepayer Bill Comparison (2009-2020)

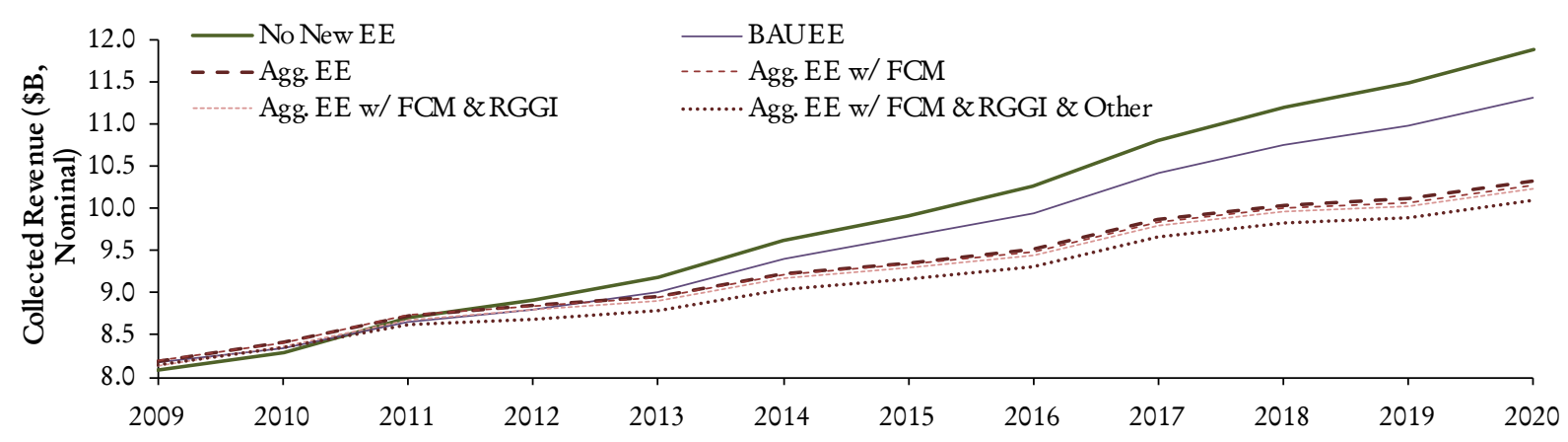

Table 2. Change in Ratepayer Bills due to Energy Efficiency (\$B, 2009-2030 PV relative to No New EE Case)

\begin{tabular}{|c|c|c|c|c|c|c|c|c|}
\hline & \multicolumn{4}{|c|}{ EE Business Model } & \multicolumn{3}{|c|}{ Alternative Revenue Sources } & \multirow[b]{2}{*}{ Total } \\
\hline & Base & SI & LBR & Subtotal & FCM & RGGI & Other & \\
\hline 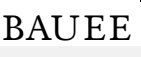 & -3.81 & 0.05 & 0.26 & -3.50 & & & & -3.50 \\
\hline Agg. EE & -10.02 & 0.17 & 0.71 & -9.15 & -0.21 & -0.34 & -0.66 & -10.35 \\
\hline
\end{tabular}

Customer rate impacts from energy efficiency show the opposite trend from bills with substantial increases in rates as savings levels rise; these rate impacts are modestly offset by alternative EE revenue sources. If no new energy efficiency programs are implemented, all-in 
retail rates increase from $21.4 \mathrm{\$} / \mathrm{kWh}$ in 2009 to $30.2 \mathrm{\$} / \mathrm{kWh}$ in 2020 , in nominal terms (see Figure 5), a 3.2\% per year increase in retail rates. In each year, retail rates under the BAU EE portfolio are, on average, $\sim 0.7 \mathrm{\$} / \mathrm{kWh}$ higher than the retail rates under the No New EE scenario between 2009 and 2020, and are $\sim 1.1$ / / kWh higher over the entire 22 year analysis period (2009-2030) (see Table 3). If the Aggressive EE portfolio is introduced without any of the additional EE revenue sources (i.e., Aggressive EE in Table 3), then annual retail rates will be higher overall, by $\sim 3.7$ \$/kWh on average between 2009 and 2030, and will grow more rapidly, at a rate of $4.4 \%$ during that same time period, as the reduction in sales exceeds the utility cost savings from EE. ${ }^{16}$ Introducing the additional sources of revenue to offset ratepayers' share of utility EE program costs produces a modest impact on average all-in retail rates (see Figure 5), dropping them by roughly $0.06 \$ / \mathrm{kWh}$ if either FCM or RGGI revenues are applied respectively and by $0.13 \$ / k W h$ if Other Funding Sources are found (see Table 3).

Figure 5. Nominal All-In Retail Rate Comparison (2009-2020)

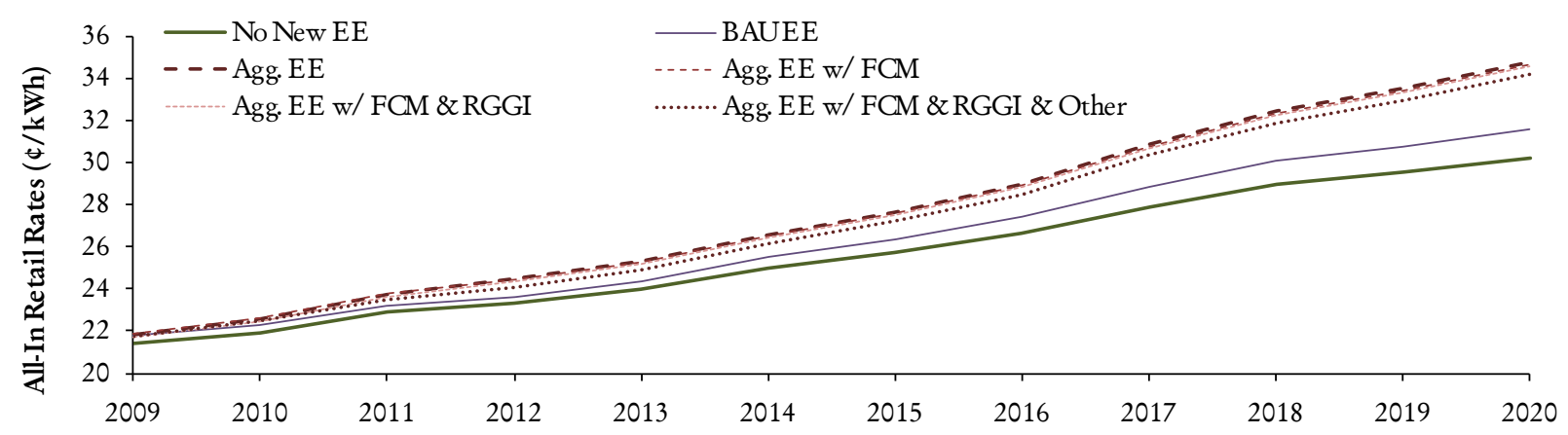

Table 3. Change in All-In Retail Rates due to Energy Efficiency (\$/kWh, 2009-2030 average relative to No New EE Case)

\begin{tabular}{ccccccccc} 
& & \multicolumn{4}{c}{ EE Business Model } & & \multicolumn{3}{c}{ Alternative Revenue Sources } & \\
& Base & SI & LBR & Subtotal & FCM & RGGI & Other & Total \\
\cline { 2 - 4 } BAUEE & 1.04 & 0.01 & 0.04 & 1.09 & & & & 1.09 \\
Agg. EE & 3.51 & 0.03 & 0.13 & 3.67 & -0.06 & -0.06 & -0.13 & 3.43
\end{tabular}

\subsection{Impact of Aggressive EE Portfolio on Utility Shareholders}

Utility shareholders are concerned about the impact of aggressive EE programs on their earnings and ROE. Without any new energy efficiency programs, the "super-utility" would have an average return of $9.17 \%$ during the $2009-2030$ period, which falls below their authorized level of 10.98\%, and would report total after-tax earnings of 3.49B (PV) (see Figure 6 and Figure ). Under the BAU EE portfolio, the utility's earnings are reduced by $\sim \$ 370 \mathrm{M}(\mathrm{PV})$ and average

\footnotetext{
${ }^{16}$ All-in retail rates are a function of the utility's revenue requirement in the numerator and sales in the denominator. Mathematically, a unit decrease in the numerator will decrease the fraction, ceteris paribus, while a unit decrease in the denominator will increase the fraction, ceteris paribus. In this case, both the numerator and denominator are being reduced. In percentage terms, sales (denominator) are dropping much faster than the revenue requirement (numerator), so retail rates (the fraction) will increase.
} 
ROE decreases by 92 basis points compared to a situation without any new EE programs. However, the implementation of a shareholder incentive (SI) mechanism and lost base revenue (LBR) mechanism would increase earnings and ROE by $\sim$ \$200M (PV) and 54 basis points, respectively. If the "super-utility" achieves the savings goals in the Aggressive EE portfolio, earnings decrease by $\sim$ \$1.06B (PV), and ROE drops by over 270 basis points. ${ }^{17}$ However, the EE business model increases utility earnings by $\sim \$ 550 \mathrm{M}(\mathrm{PV})$ and improves the average ROE by 154 basis points. Implementing our decoupling mechanism (with a k-factor of 1.14\%) which completely removes the effect on shareholder returns from the reduction in revenue due to lower sales, instead of the lost base revenue recovery mechanism, provides $\sim \$ 970 \mathrm{M}(\mathrm{PV})$ in earnings and contributes 273 basis points on average to ROE. Thus, combining this decoupling mechanism with the MA shareholder incentive provides a business model that improves ROE $(9.47 \%)$ and provides slightly higher overall earnings to utility shareholders $(\$ 20 \mathrm{M})$ if they achieve the savings goals in the Aggressive EE portfolio.

Figure 6. Effects of Alternative Efficiency Business Models Components on ROE (2009-2030)

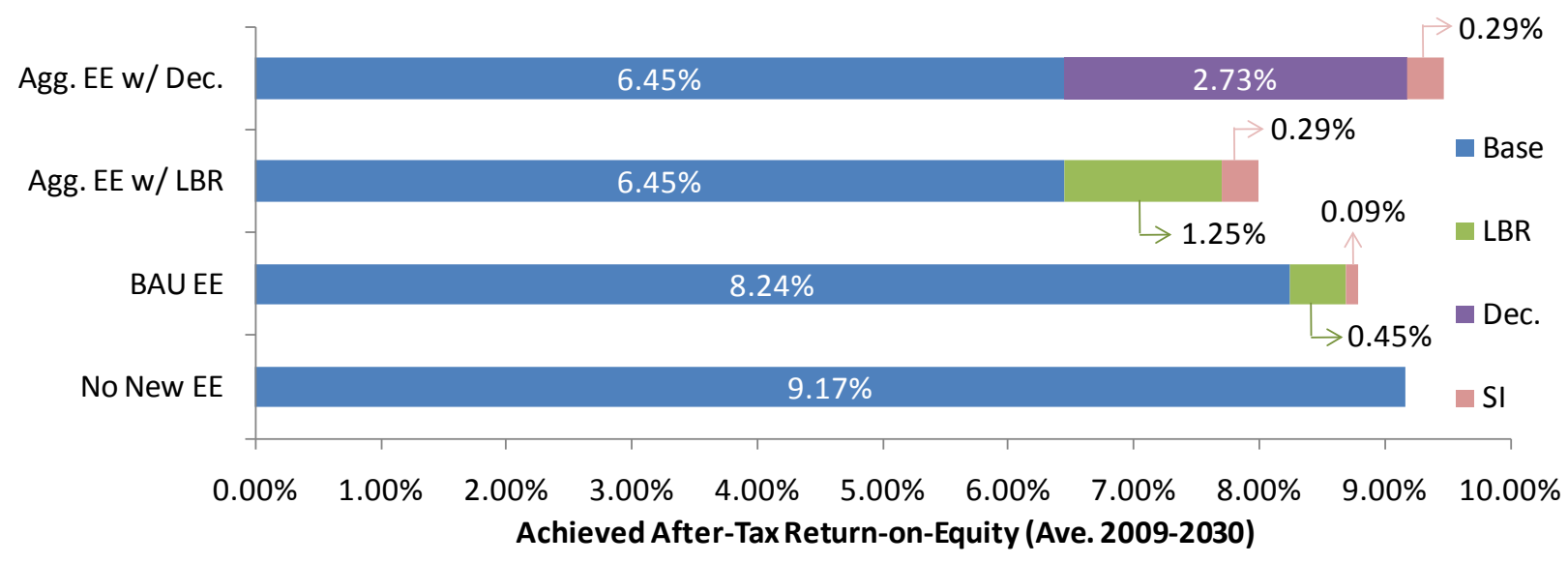

\footnotetext{
${ }^{17}$ The application of alternative EE revenue sources to reduce ratepayers' share of utility EE program costs has no bearing on the financial standing of shareholders.
} 
Figure 7. Effects of Alternative Energy Efficiency Business Model Components on Earnings (2009-2030)

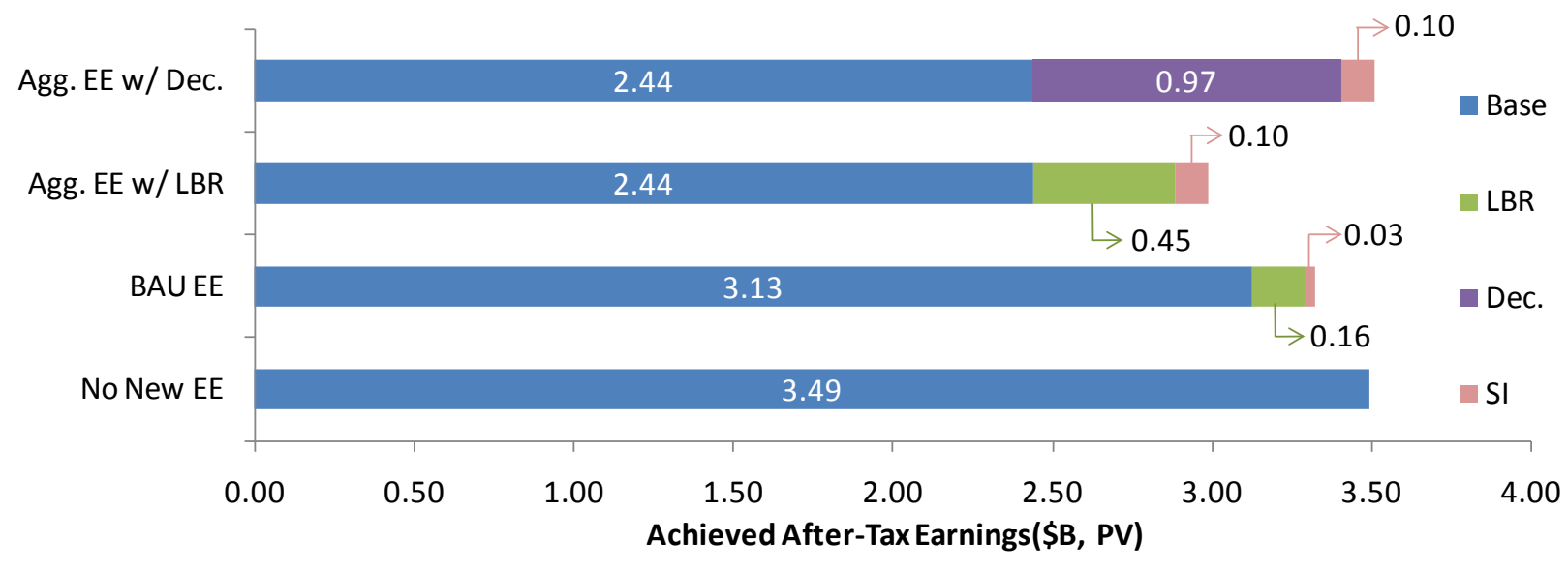

The incremental cost of the decoupling mechanism, relative to the lost base revenue mechanism, to ratepayers would be $\sim \$ 830 \mathrm{M}$, on a PV basis during the analysis period, and would raise all-in retail rates on average by $1.5 \mathrm{mills} / \mathrm{kWh}$. Even with this added cost, ratepayers as a whole would still see aggregate bill savings of \$8.9B (PV) between 2009 and 2030 under the Aggressive EE portfolio.

\section{Conclusions}

This analysis quantifies the impacts on ratepayers and shareholders when a state like Massachusetts pursues alternative energy efficiency goals: $\sim 0.9 \%$ of retail sales (BAU EE) versus $\sim 2.4 \%$ of retail sales (Aggressive EE), through ratepayer-funded programs offered by its electric operating companies. We focus on the ability for additional revenue sources to mitigate rate and bill impacts on ratepayers when a Massachusetts "super-utility" achieves the Aggressive EE savings goal, which provides substantial utility bill savings for customers. We also evaluate the ability of a decoupling mechanism to mitigate the financial impact on utility shareholders.

If Massachusetts successfully implements an Aggressive EE portfolio between 2009 and 2020 , with annual energy savings of $\sim 2.4 \%$ of retail sales and net resource benefits of $\$ 11.2 \mathrm{~B}$ (PV), customer bills over the lifetime of the installed measures (2009-2030) in aggregate are lower by $\$ 5.6 \mathrm{~B}$ ( $\sim 5.5 \%$ lower) compared to continuing on a path of EE prior to passage of the GCA (i.e., BAU EE). These bill savings account for and are net of any rate increases necessary to fund the increased energy efficiency. These Aggressive EE portfolios are unprecedented and as a practical matter mean that nearly all customers would likely participate over this 12 year period. However, rates are $\sim 4.7 \mathbb{\$} / \mathrm{kWh}$ higher in 2030 ( 10\%) under the Aggressive EE scenario compared to the BAU EE scenario. If some portion of EE program costs are paid by revenues from FCM, RGGI and other funding sources (\$1.2B PV or 35\% of utility program costs), these multiple funding sources have the effect of mitigating $7 \%$ of the average annual rate impacts of our Aggressive EE portfolio between 2009 and 2030. If these alternative funding sources were not utilized, retail rates would have been 6 mills/kWh higher in 2020. 
Our analysis also suggests that the utility faces significant erosion in earnings and a lower ROE as more aggressive energy efficiency programs are implemented. Utility earnings are $\sim$ \$330M (PV) lower under the Aggressive EE scenario compared to the BAU EE scenario even with shareholder incentives and a lost base revenue mechanism. Our analysis shows that it is possible to design a decoupling mechanism with a k-factor (i.e., net inflation factor) of 1.14\% that allows the utility to remove the effect on the utility's achieved ROE from the lower sales and thus reduced recovery of fixed costs (i.e., ROE of 9.67\%). With the implementation of a decoupling mechanism designed in this fashion with a shareholder incentive that provides the super-utility with $3 \%$ of program costs on an after-tax basis, shareholder returns would grow by 68 basis points and earnings would rise by $\sim \$ 190 \mathrm{M}$ (PV) between 2009 and 2030 in comparison to the BAU EE scenario. Even if the DPU implements this type of decoupling mechanism, aggregate customer bills are still $\sim$ \$5.4B (PV) lower in relation to what would have occurred under the BAU EE scenario.

This study provides some insights for policymakers and regulators interested in pursuing very aggressive energy efficiency goals. As states adopt very aggressive energy efficiency policy goals, it becomes even more important for utilities to leverage other revenue streams (e.g. third party financing, revenues from carbon emission credits) in addition to ratepayer funds in order to mitigate potential rate impacts. Because an aggressive energy efficiency portfolio provides significant societal benefits in Massachusetts (compared to supply-side alternatives), our results also suggest that it is possible for regulators, utilities and other stakeholders to design a business model that aligns the financial interests of utility program administrators with the state's clean energy policy goals. 


\section{References}

Barbose, G., C. Goldman, and J. Schlegel, 2009. “The Shifting Landscape of Ratepayer-Funded Energy Efficiency in the U.S.” The Electricity Journal 22(8):29-44.

Cappers, P., C. Goldman, M. Chait, G. Edgar, J. Schlegel, and W. Shirley, 2009a.

"Financial Analysis of Incentive Mechanisms to Promote Energy Efficiency: Case Study of a Prototypical Southwest Utility.” LBNL-1598E. Berkeley, Calif.: Lawrence Berkeley National Laboratory.

Cappers, P. and C. Goldman, 2009b. "Empirical Assessment of Shareholder Incentive Mechanisms Designs under Aggressive Savings Goals: Case Study of a Kansas "Super-Utility".” LBNL-2492E. Berkeley, Calif.: Lawrence Berkeley National Laboratory.

Cappers, P. and C. Goldman, 2009c. "Financial Impact of Energy Efficiency Under a Federal Renewable Electricity Standard: Case Study of a Kansas "Super-Utility"” LBNL-2924E. Berkeley, Calif.: Lawrence Berkeley National Laboratory.

Eldridge, M., M. Sciortino, L. Furrey, S. Nowak, S. Vaidyanathan, M. Meubauer, N. Kaufman, A. Chittum, S. Black, C. Sheppard, C. Chamberlin, A. Jacobsen, Y. Mugica and D. Bryk, 2009. "The 2009 State Energy Efficiency Scorecard.” ACEEE E097. Washington, D.C.: American Council for an Energy-Efficient Economy.

Hornby, R., P. Chernick, C. Swanson, D. White, I. Goldman, B. Grace, B. Biewald, C. James, B. Warfield, J. Gifford, and M. Chang, 2009. “Avoided Energy Supply Costs in New England: 2009 Report.” Report Prepared for Avoided-Energy-Supply-Component (AESC) Working Group. Cambridge, Mass.: Synapse Energy Economics, Inc.

Jensen, V., 2007. “Aligning Utility Incentives with Investment in Energy Efficiency: A Product of the National Action Plan for Energy Efficiency.” Fairfax, Va.: ICF International, Inc.

Mass. Gen. Laws ch. 164, § 1A. An Act Relative to Restructuring the Electric Industry in the Commonwealth, Regulating the Provision of Electricity and Other Services, and Promoting Enhanced Consumer Protections Therein. 1997 Mass. Acts 164. November 1997.

Mass. Gen. Laws ch. 25, § 21. An Act Relative to Green Communities. 2008 Mass. Acts 169. 2 July 2008. 